\title{
Regulation of Biliary Lipid Secretion by mdr2 P-Glycoprotein in the Mouse
}

\author{
Ronald P. J. Oude Elferink, ${ }^{\star}$ Roel Ottenhoff, ${ }^{*}$ Michel van Wijland, * Jaap J. M. Smit, ${ }^{\star}$ Alfred H. Schinkel, ${ }^{\star}$ \\ and Albert K. Groen* \\ ${ }^{*}$ Department of Gastrointestinal and Liver Diseases, Academic Medical Center; and ${ }^{\ddagger}$ Section of Molecular Biology, Netherlands Cancer \\ Institute, Amsterdam, The Netherlands
}

\begin{abstract}
Disruption of the $m d r 2$ gene in mice leads to a complete absence of phospholipid from bile (Smit, J. J. M., et al. 1993. Cell. 75:451-462). We have investigated the control of both mdr2 P-glycoprotein (Pgp) expression and bile salt secretion on biliary lipid secretion in the mouse. Lipid secretion was monitored at various bile salt output rates in wildtype mice $(+/+)$, heterozygotes $(+/-)$, and homozygotes $(-/-)$ for $m d r 2$ gene disruption. In $(-/-)$ mice, phospholipid secretion was negligible at all bile salt output rates. In $(+I-)$ mice, a curvilinear relation between bile salt and phospholipid secretion was observed similar to that in $(+I$ + ) mice; however, at all bile salt secretion rates phospholipid secretion was reduced compared to $(+/+)$ mice, indicating that mdr2 Pgp exerts a strong control over secretion.

Infusion of increasing amounts of taurocholate up to maximal secretory rate led to a decline in the phospholipid and cholesterol secretion in both $(+/+)$ and $(+/-)$ mice in accordance to what has been observed in other species. In contrast, in $(-/-)$ mice cholesterol secretion increased under these conditions while phospholipid output remained extremely low. The increased cholesterol secretion may represent extraction of cholesterol from the canalicular plasma membrane by taurocholate micelles as opposed to the concomitant secretion of both phospholipid and cholesterol in the presence of a functional mdr2 Pgp.

Increased bile flow in $(-/-)$ mice could be attributed completely to an increase in the bile salt-independent fraction and may therefore be caused by the bile duct proliferation in these mice. (J. Clin. Invest. 1995. 95:31-38.) Key words: phospholipids $\bullet$ cholesterol $\bullet$ bile salts $\cdot$ P-glycoprotein • liver
\end{abstract}

\section{Introduction}

Biliary phospholipid secretion serves at least two functions. On the one hand it ensures solubilization of cholesterol and on the other hand it mitigates the detergent action of the high

A portion of these results was presented at the 44th Meeting of the American Association for the Study of Liver Diseases in Chicago, IL on 4-7 November 1993.

Address correspondence to Ronald Oude Elferink, Ph.D., Department of Gastrointestinal and Liver Diseases, Academic Medical Center, FO-116, Meibergdreef 9, 1105 AZ Amsterdam, The Netherlands. Phone: 20-566-3828; FAX: 20-691-7033.

Received for publication 6 June 1994 and in revised form 24 August 1994.

J. Clin. Invest.

(C) The American Society for Clinical Investigation, Inc.

0021-9738/95/01/0031/08 \$2.00

Volume 95, January 1995, 31-38 concentrations of bile salts in the biliary tree. It has been demonstrated in several model systems $(1-3)$ that the presence of phospholipid and cholesterol greatly reduces the otherwise cytotoxic action of bile salts. The mechanism by which these lipids enter bile is not known although several models have been proposed (4-6). In many studies a clear-cut relation has been observed between the secretion rate of bile salts and biliary lipids (7-9). Because of the detergent activity of the micellar bile salt concentrations in the canaliculus, it is generally assumed that bile salts act at this level to solubilize lipids from the membrane and indirect evidence for this assumption exists $(10,11)$. However, bile salts may also promote the transhepatic flux of biliary lipids at other levels, like phospholipid synthesis (12) and intracellular transport via lipid vesicles $(13,14)$ and/ or via phosphatidylcholine $(\mathrm{PC})^{1}$ transport protein $(15,16)$.

It was demonstrated recently that mdr2 P-glycoprotein (Pgp) in the canalicular membrane of the mouse plays a crucial role in the secretion of phospholipids into bile (17). Mice in which the $m d r 2$ gene was disrupted by homologous recombination [ $m d r 2(-/-)$ mice] displayed a complete absence of phospholipids in bile and a strong depression of cholesterol secretion. The latter observation is in line with the fact that phospholipid and cholesterol are secreted into bile in a coordinate fashion (9). In addition to a reduced lipid secretion, other abnormalities were also observed in $(-/-)$ mice: bile flow and biliary chloride secretion were significantly increased and glutathione secretion was strongly diminished. Heterozygous $(+/-)$ mice, which are expected to have $50 \%$ of the normal expression of this gene, had a significantly reduced phospholipid secretion ( $60 \%$ of normal) and this was the only abnormality observed in these animals. It was therefore proposed that the loss of phospholipid secretion was the primary consequence of the $m d r 2$ gene disruption.

The highly homologous mdr1 Pgp has been characterized as an ATP-dependent transporter of amphipathic cationic and neutral compounds (for review see reference 18). Overexpression of this protein renders cells resistant to toxic amphipaths by reducing the intracellular content of these compounds. Overexpression of mdr2 Pgp in cells does not confer this resistance and it has therefore been postulated that this protein may have a different substrate specificity (19). Based on its homology with mdr1 it may be hypothesized that mdr2 Pgp also functions in the transmembrane movement of its substrate. In view of our previous observations, (one of) the potential substrate (s) is most likely PC. An attractive possibility is that mdr2 Pgp acts as a flippase in the transport of phospholipid from the inner to the outer leaflet of the canalicular membrane. A flippase-like function has also been suggested for the mdrl Pgp homologue $(20,21)$.

Since PC secretion was hitherto thought to be primarily

1. Abbreviations used in this paper: ER, endoplasmic reticulum; PC, phosphatidylcholine; Pgp, P-glycoprotein. 
driven by bile salt secretion, we have investigated the relation between bile salt and phospholipid secretion in normal $(+/+)$ mice and in mice heterozygous $(+/-)$ and homozygous $(-l$ - ) for the $m d r 2$ gene disruption.

\section{Methods}

Animals. The generation of mice that are homozygous $(-/-)$ and heterozygous $(+l-)$ for the $m d r 2$ gene disruption with the 129/Ola strain $(+/+)$ as genetic background has been described by Smit et al. (17). All mice including 129/Ola controls were bred in our own colony and were used for experiments at 2-4 mo of age. The animals were anesthetized by intraperitoneal injection of $1 \mathrm{ml} / \mathrm{kg}$ Hypnorm (fentanyl/ fluanisone) and $10 \mathrm{mg} / \mathrm{kg}$ diazepam. The abdomen was opened and the gallbladder was cannulated after distal ligation of the common bile duct. In some experiments, taurocholate (30 $\mathrm{mM}$ in PBS) was infused into the tail vein at the indicated rate. Directly after cannulation, bile sampling was started and continued for up to $2 \mathrm{~h}$. The body temperature was maintained by placing the animals on a thermostatted heating pad and by covering them with a piece of tin foil. Bile samples were collected on ice and immediately frozen at $-20^{\circ} \mathrm{C}$. Bile flow was determined gravimetrically assuming a density of $1 \mathrm{~g} / \mathrm{ml}$ for bile.

Assays. Total phospholipid was determined enzymatically with phospholipase D and choline oxidase (22). Cholesterol was assayed enzymatically with cholesterol oxidase (23). Total bile salt concentration was measured spectrophotometrically with $3 \alpha$-hydroxysteroid dehydrogenase (24). Lipid composition of selected bile samples was also assessed by thin layer chromatography. Samples were chromatographed on silica gel DC plates (Merck, Darmstadt, Germany) with chloroform/ methanol/acetic acid/ $\mathrm{H}_{2} \mathrm{O}$ (100:20:12:5 by volume) as eluent. The lipids were visualized by spraying with phosphomolybdic acid/ethanol $(10: 90[\mathrm{wt} / \mathrm{vol}])$ followed by methanol/sulfuric acid $(1: 1[\mathrm{vol} / \mathrm{vol}])$ and heating at $120^{\circ} \mathrm{C}$.

For the determination of total lipid content, livers were excised, immediately freeze clamped, and stored at $-70^{\circ} \mathrm{C}$ until further use. Subsequently, the tissue was subjected to Folch extraction. After evaporation of the organic solvent, the extract was dissolved in isopropanol and in these samples cholesterol and phospholipid were measured enzymatically as above.

Bile salts from selected bile samples were conjugated to their methyl esther acetates and separated by capillary gas chromatography as described by Parmentier et al. (25) and the different species were detected by mass spectrometry with selected ion monitoring.

Chemicals. All chemicals used were from Sigma Immunochemicals (St. Louis, MO). The phospholipid assay kit was from Wako Chemicals GmbH (Neuss, Germany). Cholesterol assay kit was from Boehringer Mannheim (Mannheim, Germany). 3-OH-steroid dehydrogenase was from Worthington Biochemical Corp. (Freehold, NJ).

Statistics. All values represent means \pm standard deviation from at least three animals of each genotype. Differences between the groups were analyzed by unpaired, two-tailed Student's $t$ test.

\section{Results}

Relationship between biliary bile salt and lipid secretion. To evaluate the relation between bile salt and lipid secretion, mice were cannulated via the gallbladder after distal ligation of the common bile duct. This leads to interruption of the enterohepatic cycle and to subsequent time-dependent depletion of the bile salt pool. Samples were collected during $2 \mathrm{~h}$ of bile diversion. Fig. 1 illustrates the data from a representative experiment with a control $(+/+)$ mouse and shows that within 60-90 min bile salt secretion was reduced to an almost stable level of $\sim 20 \%$ of initial output. As a consequence of the reduced bile salt output there was also a time-dependent reduction of bile flow (Fig. $1 A$ ). A similar pattern of decreasing output was found for phospholipids and cholesterol (Fig. $1 B$ ). Using this
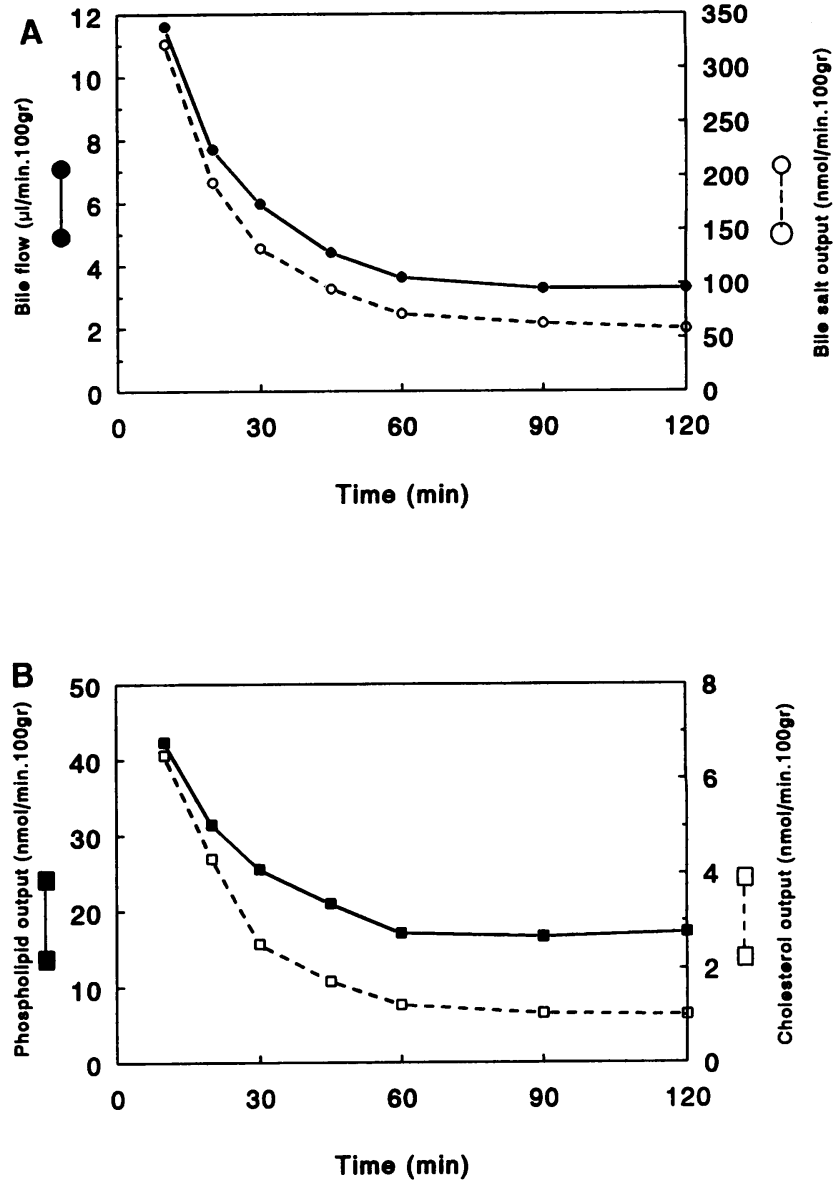

Figure 1. Time-dependent depletion of the bile salt pool after interruption of the enterohepatic cycle in the mouse. The figure shows a representative experiment with a control mouse. Directly after cannulation of the gallbladder, bile was collected for the indicated time periods. $A$, bile flow $(\bullet)$ and bile salt output $(O)$. B, phospholipid output $(\square)$ and cholesterol output ( $\square$ ).

experimental setup the relationships between bile salt output and phospholipid and cholesterol output were determined for the three mouse genotypes: wild-type $(+/+)$ mice, heterozygous $(+/-)$, and homozygous $(-l-)$ mice for $m d r 2$ gene disruption (six animals of each genotype). The phospholipid output rates that were obtained at the different time points were plotted against the bile salt output rates at the same time points. Fig. $2 A$ shows that in normal mice a curvilinear relation between phospholipid and bile salt secretion was observed, in agreement with what has been reported for other species. In the $(+/-)$ mice, a similar relation was found, but phospholipid secretion was $30-50 \%$ lower than in normal mice at all bile salt output rates. In the $(-/-)$ mice, phospholipid secretion was extremely low to absent $(<0.5 \mathrm{nmol} / \mathrm{min}$ per $100 \mathrm{~g})$. The data obtained with the $(+/-)$ mice demonstrate that even at low bile salt secretion rates the level of $m d r 2$ expression controls phospholipid secretion.

When cholesterol secretion was plotted against bile salt secretion (Fig. 2 B) a curvilinear relation was also observed, but there was no significant difference between $(+/+)$ and $(+/$ $-)$ mice. As a consequence the cholesterol/phospholipid ratio tended to be higher in the $(+/-)$ mice than in the $(+/+)$ mice, but the average values were not significantly different 

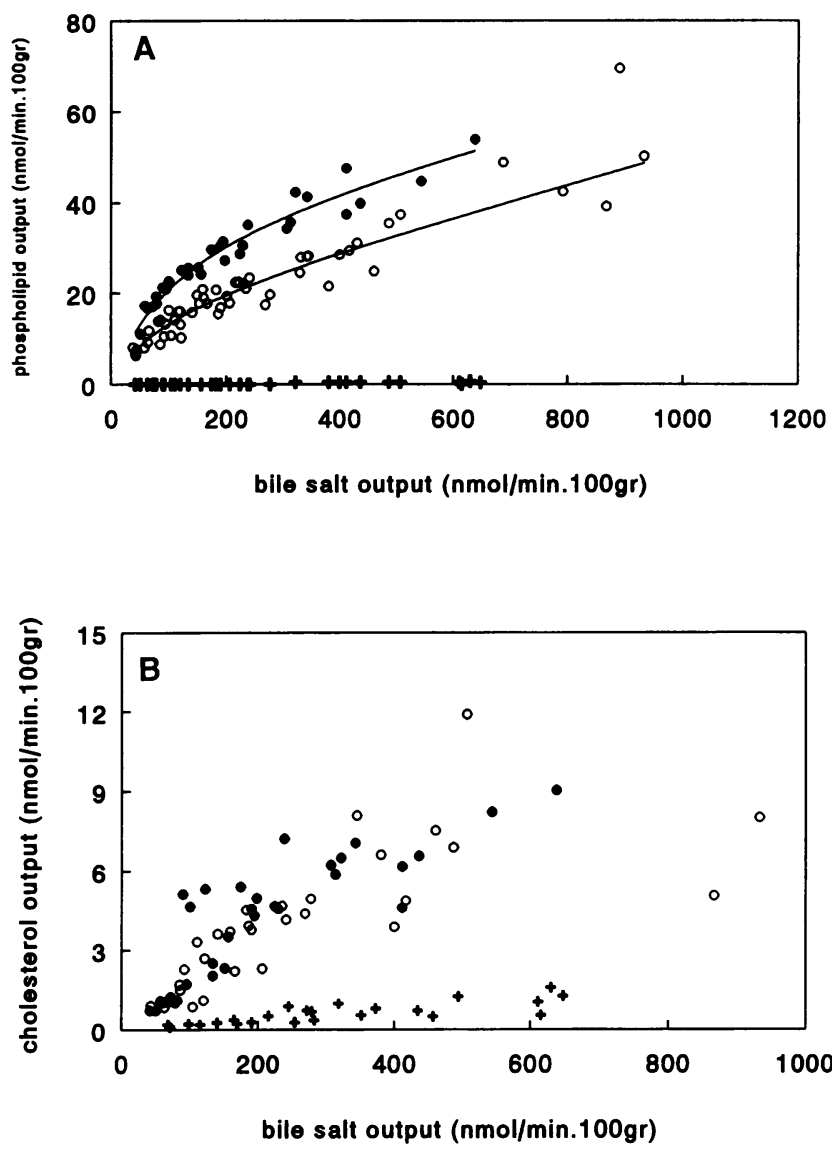

Figure 2. Relation between bile salt and phospholipid secretion in the three mouse genotypes. The data represent all separate measurements from six animals of each genotype in an experimental setup as shown in Fig. 1. $A$, phospholipid secretion; $B$, cholesterol secretion. $\bullet,(+/+)$ mice; $O,(+/-)$ mice;,$+(-/-)$ mice.

[0.136 \pm 0.053 in $(+/+)$ and $0.194 \pm 0.068$ in $(+/-)$ mice ]. In the $(-I-)$ mice, the secretion of cholesterol was very low (Fig. $2 \mathrm{~B}$ ). At this low level, however, a positive relation between bile salt and cholesterol output was observed.

Since in each mouse genotype the bile salt output is reduced to an almost stable low level after $60 \mathrm{~min}$ of interruption of the enterohepatic circulation (Fig. 1), summation of the total amount of bile salts secreted up to $60 \mathrm{~min}$ yields an estimate of the total bile salt pool. The bile salt pool in $(-/-)$ mice $(19.6 \pm 2.7 \mu \mathrm{mol} / 100 \mathrm{~g})$ was significantly higher than in $(+/$ $+)$ mice $(12.6 \pm 5.1 \mu \mathrm{mol} / 100 \mathrm{~g} ; P=0.014 ; n=6)$. The size of the pool in $(+/-)$ mice was intermediate $(15.8 \pm 4.7 \mu \mathrm{mol} /$ $100 \mathrm{~g})$, but this did not differ significantly from $(+/+)$ or $(-/-)$ mice.

Liver phospholipid and cholesterol content in the three mouse genotypes. Table I shows that livers from all genotypes have a comparable content of phospholipids but that the cholesterol content is significantly increased in $(-/-)$ mice by $40 \%$. An intermediate content was observed in $(+/-)$ mice $(13 \%$ increase compared with controls), but this was not significant.

Regulation of lipid secretion at the maximal secretory rate of taurocholate. Lipid secretion in the three mouse genotypes was also analyzed when bile salt output levels were increased to levels above the endogenous output rate. To this end, increasing amounts of taurocholate were continuously infused into the tail
Table I. Phospholipid and Cholesterol Content of the Liver

\begin{tabular}{llll}
\hline Mouse genotype & $(+/+)$ & $(+/-)$ & $(-/-)$ \\
\hline \multicolumn{4}{c}{$\mu m o l / g d r y w t$} \\
Phospholipid & $69.5 \pm 4.0$ & $75.6 \pm 4.7$ & $73.7 \pm 4.7$ \\
Cholesterol & $19.4 \pm 2.0$ & $22.1 \pm 2.7$ & $27.3 \pm 2.7 *$ \\
& & & \\
\hline
\end{tabular}

Livers from the three mouse genotypes were extracted and phospholipids and cholesterol were measured as described in Methods. Data represent means \pm SD from three animals of each genotype. * Significant difference $(P<0.05)$ between $(+/+)$ and $(-/-)$ mice.

vein of the mice during collection of bile. The infusion started at $400 \mathrm{nmol} / \mathrm{min}$ per $100 \mathrm{~g}$, which is about equal to the endogenous output rate, and the infusion rate was increased every $30 \mathrm{~min}$ to a maximal value of $1,600 \mathrm{nmol} / \mathrm{min}$ per $100 \mathrm{~g}$. Fig. $3 \mathrm{~A}$ shows that in all three genotypes bile salt secretion first decreased during the initial $30 \mathrm{~min}$, probably because the initial infusion rate was insufficient to counteract the initial depletion of the bile salt pool. After 30-40 min, bile salt output started to increase and attained a stable maximal transport rate after 80 min which was lower than the rate of infusion, indicating that the maximal secretory rate $\left(S_{m}\right)$ was reached. The $S_{m}$ was $1,230 \mathrm{nmol} / \mathrm{min}$ per $100 \mathrm{~g}$ in $(+/+)$ mice, $810 \mathrm{nmol} / \mathrm{min}$ per $100 \mathrm{~g}$ in $(+/-)$ mice, and $679 \mathrm{nmol} / \mathrm{min}$ per $100 \mathrm{~g}$ in $(-/-)$ mice, the latter being only $\sim 30 \%$ above the endogenous output rate (Table II). Thus, maximal bile salt secretion capacity is significantly reduced with deletion of each $m d r 2$ allele.

In $(+/+)$ and $(+/-)$ mice, phospholipid secretion (Fig. 3 $C$ ) initially followed bile salt output. However, after $70 \mathrm{~min}$ when the maximal bile salt output was almost reached phospholipid output started to decline. At all bile salt output rates the secretion of phospholipid was significantly lower in $(+/-)$ than in $(+/+)$ mice. In $(-/-)$ mice, phospholipids became detectable when taurocholate was infused at the maximal dose (average phospholipid secretion rate of $1.5 \mathrm{nmol} / \mathrm{min}$ per 100 g). This secretion rate was, however, only $3 \%$ of that in $(+/$ $+)$ mice.

In $(+/+)$ and $(+/-)$ mice, cholesterol secretion (Fig. 3 $D)$ more or less paralleled phospholipid secretion in that the output rate started to decrease when maximal bile salt secretion was reached (Fig. $3 D$ ). In contrast, in $(-/-$ ) animals cholesterol secretion increased from very low levels $(<0.3 \mathrm{nmol} / \mathrm{min}$ per $100 \mathrm{~g}$ ) at the start of the experiment to output rates similar to those observed in controls and heterozygotes during maximal bile salt infusion. Thus, although the bile salt output in $(-/-)$ animals did not increase substantially during the experiment, cholesterol secretion increased $\sim 10$-fold to $2.2 \mathrm{nmol} / \mathrm{min}$ per $100 \mathrm{~g}$ during maximal bile salt infusion.

Analysis of the bile salt composition. To investigate if the increase in the cholesterol secretion in $(-/-)$ mice might be caused by a change in the bile salt pool composition during the infusion of taurocholate, we analyzed bile salt species before and after taurocholate infusion (Table III).

Analysis of bile salt species in the first bile sample (i.e., before infusion) revealed that the composition of the endogenous bile salt pool is similar in $(+/+)$ and $(-/-)$ mice: 38 and $29 \%$ of total bile salts was cholate while 59 and $69 \%$ consisted of muricholate in $(+/+)$ and $(-/-)$ mice, respectively. Three isomers with the mass spectrum of muricholate were detected, the main form $(72 \%)$ being $\beta$-muricholate. The 

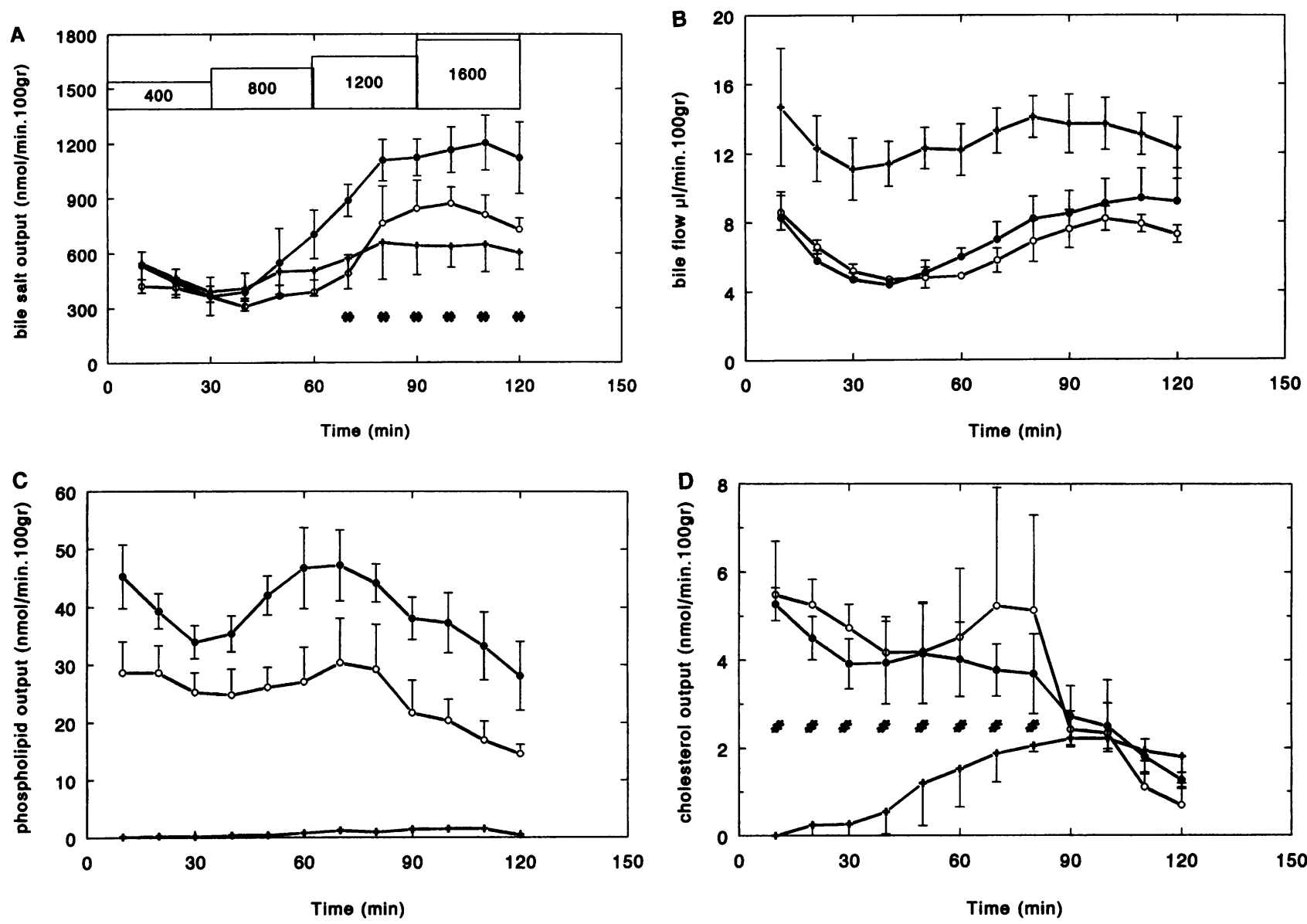

Figure 3. Secretion of the different bile components in the mouse during intravenous administration of increasing amounts of taurocholate. Mice were cannulated in the gallbladder, and directly after starting bile collection taurocholate was infused into the tail vein at the indicated rate. $\bullet,(+/+)$ mice; $0,(+/-)$ mice;,$+(-/-)$ mice. $A$, bile salt secretion; $B$, bile flow; $C$, phospholipid secretion; and $D$, cholesterol secretion. Data represent average \pm SD from three mice of each genotype. Differences were compared by Student's $t$ test; $*$, significant difference $(P<0.05)$ between $(+l+)$ and $(+I-)$ or $(-I-)$ mice;, significant difference $(P<0.05)$ between $(-/-)$ and $(+/+)$ or $(+/-)$ mice. All values for bile flow in $(-I-)$ mice differed significantly $(P<0.01)$ from $(+/+)$ and $(-/-)$ mice except at $120 \mathrm{~min}(+/+)$. All values for phospholipid in $(-/-)$ and in $(+/-)$ mice differed significantly from $(+/+)$ mice. Bars in $A$ indicate the rate of taurocholate infusion expressed in nanomoles per minute per $100 \mathrm{~g}$.

other two isomers probably represent $\alpha$ - and $\Omega$-muricholate. Only very low proportions of other bile salts (chenodeoxycholate, deoxycholate, and ursodeoxycholate) were detected.

At the end of the taurocholate infusion period $(t=120)$

Table II. Maximal Secretory Rates of Taurocholate, Phospholipids, and Cholesterol

\begin{tabular}{lccc}
\hline Genotype & Taurocholate & Phospholipid & Cholesterol \\
\hline \multicolumn{4}{c}{ nmolmin per $100 \mathrm{~g}$} \\
$(+/+)$ & $1230 \pm 157$ & $54.8 \pm 2.07$ & $5.55 \pm 1.47$ \\
$(+/-)$ & $810 \pm 141^{*}$ & $27.7 \pm 6.23^{\ddagger}$ & $5.06 \pm 1.47$ \\
$(-/-)$ & $679 \pm 143^{8}$ & $2.2 \pm 2.1^{\ddagger}$ & $2.35 \pm 0.87^{\S}$ \\
\hline
\end{tabular}

Taurocholate was infused intravenously at the rates indicated in Fig. 3 and the secretion of bile salts, phospholipid, and cholesterol were measured. Maximal output rates were calculated for each mouse from the average output during the 30-min period of maximal secretion. Data presented are averages \pm SD for six mice of each genotype. Data from $(+/-)$ and $(-1-)$ mice were tested for difference with $(+/+)$;

${ }^{*} P<0.01,{ }^{\&} P<0.001,{ }^{\ddagger} P<0.0001$. the bile salt composition was dramatically changed, and in both $(+/+)$ and $(-I-)$ mice $>95 \%$ of the bile salts consisted of cholate (-conjugates).

Analysis of phospholipid species in bile after bile salt infu-

Table III. Bile Salt Composition of $(+/+)$ and $(-/-)$ Mice

\begin{tabular}{lcccc}
\hline \multicolumn{1}{c}{ Bile from } & $\begin{array}{c}(+/+) \\
t=0\end{array}$ & $\begin{array}{c}(+/+) \\
t=120\end{array}$ & $\begin{array}{c}(-/-) \\
t=0\end{array}$ & $\begin{array}{c}(-/-) \\
t=120\end{array}$ \\
\hline Bile salt species & & & & \\
Muricholate & $59 \pm 8$ & $2 \pm 2$ & $69 \pm 12$ & $4 \pm 4$ \\
Tauroursodeoxycholate & $2 \pm 2$ & N.D. & $1 \pm 1$ & N.D. \\
Taurocholate & $38 \pm 10$ & $98 \pm 2$ & $29 \pm 10$ & $96 \pm 4$ \\
Taurochenodeoxycholate & $1 \pm 1$ & N.D. & N.D. & N.D. \\
& & & & \\
\hline
\end{tabular}

Bile samples from the experiment in Fig. 3 were analyzed by gas chromatography-mass spectrometry to quantify the amount of the different bile salt species. Samples collected directly after cannulation $(t=0)$ were compared with samples collected during the last 10-min period of $2 \mathrm{~h}$ of increasing taurocholate infusion $(t=120)$. For experimental details, see Fig. 3. N.D., not detectable. 


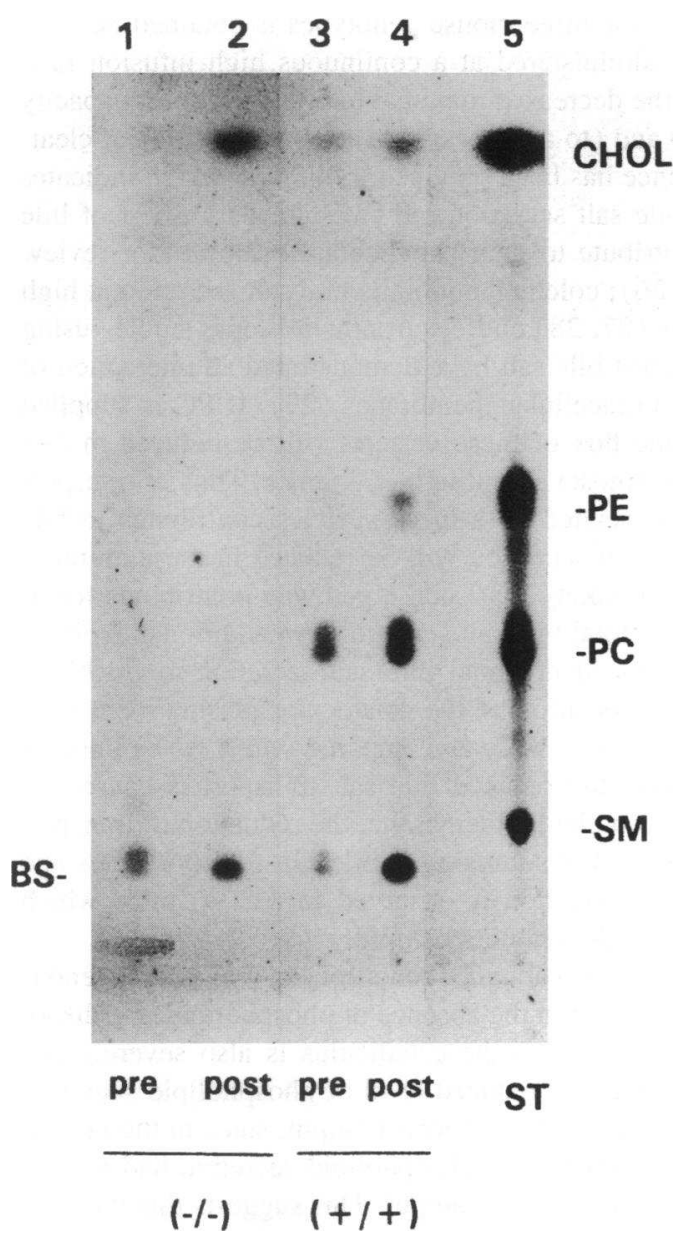

Figure 4. TLC analysis of bile phospholipids before and after infusion of taurocholate. Bile samples from the experiment in Fig. 3 were applied to a TLC plate and chomatographed as described in Methods. Samples from $(-l-)$ mice (lanes 1 and 2$)$ and $(+l+)$ mice (lanes 3 and 4 ) were taken from the first period of collection (0-10 min; pre-infusion, lanes 1 and 3) and from the last period of collection (110-120 min; post-infusion, lanes 2 and 4 ). Mixtures of standards were applied next to the bile samples ( $S T$, lane 5). $S M$, sphingomyelin; $P E$, phosphatidylethanolamine; $C H O L$, cholesterol. The lower spots (indicated by $B S$ ) in the bile samples represent bile salts.

sion. The taurocholate infusion that was performed in the experiments of Fig. 3 leads to high bile salt concentrations in the canalicular lumen. To evaluate possible aspecific extraction of phospholipids from the canalicular membrane at high taurocholate infusion rates we analyzed pre- and post-infusion bile samples by TLC (Fig. 4). Post-infusion bile samples from $(+/+)$ mice clearly contained an increased amount of phosphatidylethanolamine compared with pre-infusion samples. Sphingomyelin was not observed. In (-/-) mice, neither PC nor phosphatidylethanolamine was observed, indicating that no aspecific extraction took place. Despite the absence of phospholipids in post-infusion bile samples from $(-/-)$ mice, a clear increase in the amount of cholesterol was observed in line with the enzymatic determination shown in Fig. $3 D$.

Bile salt-dependent and-independent bile flow in the mouse genotypes. We have observed previously that bile flow is increased significantly in the $(-/-)$ mice (17). In view of the observed ductular hyperplasia in $(-/-)$ mice $(17)$, the question arose whether the increase in bile flow might represent

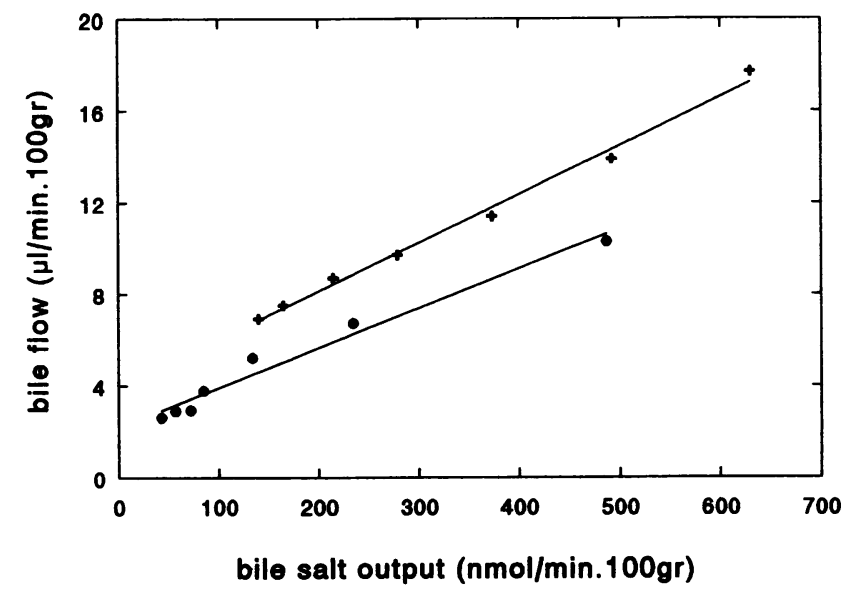

Figure 5. Relation between bile flow and bile salt secretion in a $(+/$ $+)$ mouse and a $(-1-)$ mouse. In an experimental setup as shown in Fig. 1, bile flow was measured during time-dependent depletion of the bile salt pool. The figure shows the relation between bile flow and bile salt secretion for a representative $(+/+)$ mouse and a $(-/-)$ mouse. - $(+/+)$ mouse;,$+(-/-)$ mouse. Extrapolation of this relation to the ordinate yields the theoretical value for the flow in the absence of bile salt secretion (bile salt-independent fraction of bile flow) in microliters per minute per $100 \mathrm{~g}$. The slope of the line yields the bile saltdependent bile flow in microliters of $\mathrm{H}_{2} \mathrm{O}$ per micromole of bile salt. Table III gives the means \pm SD of these values from six animals of each genotype.

ductular water flow. This would result in an increased bile saltindependent bile flow. To assess the contribution of the bile acid-dependent and -independent fraction, bile flow was determined in the experiments described in Figs. 1 and 2 and plotted against bile salt secretion. Fig. 5 demonstrates a representative experiment with $\mathrm{a}(+/+)$ and a $(-/-)$ mouse. This figure shows that in the mouse a linear relation is also obtained between bile salt output and bile flow. Extrapolation of this relationship to zero bile salt output gives the (theoretical) contribution of bile salt-independent bile flow to total bile flow. This relation was determined in six animals of each genotype and the results are given in Table IV. Bile salt-dependent bile flow (the amount of water generated per $\mu$ mole of bile salt) was similar in all mouse genotypes. On the other hand, the bile saltindependent bile flow was significantly increased in $(-/-)$ mice $(4.3 \pm 0.7 \mu \mathrm{l} / \mathrm{min}$ per $100 \mathrm{~g})$ compared with normal and heterozygous mice $(1.2 \pm 1.1$ and $1.4 \pm 0.9 \mu \mathrm{l} / \mathrm{min}$ per $100 \mathrm{~g})$.

Table IV. Bile Salt-dependent and-independent Bile Flow in the Three Mouse Genotypes

\begin{tabular}{lcc}
\hline Fraction of bile flow & Bile salt-dependent flow & Bile salt-independent flow \\
\hline & $\mu l / \mu \mathrm{mol}$ & $\mu l /$ min per $100 \mathrm{~g}$ \\
Mouse genotype & & \\
$(+/+)$ & $20.0 \pm 10.7$ & $1.2 \pm 1.1$ \\
$(+/-)$ & $15.4 \pm 2.7$ & $1.4 \pm 0.9$ \\
$(-/-)$ & $18.3 \pm 3.5$ & $4.3 \pm 0.7 *$ \\
\hline
\end{tabular}

Bile salt-dependent and -independent flow were determined as described in Fig. 5. The data represent means \pm SD and are from six animals of each genotype. Data from $(+/-)$ and $(-l-)$ mice were tested for difference with $(+/+) ; * P<0.001$. 


\section{Discussion}

Bile salts are generally regarded as the primary agonists in the secretory mechanism of biliary lipids. This report extends our initial observation that mdr2 Pgp also plays a central role in this process (17). In mice with a disrupted $m d r 2$ gene, phospholipid secretion was negligible and with $50 \%$ of normal expression secretion was depressed at all bile salt secretion rates. In accordance with results for other species, in $(+/+)$ mice the relation between bile salt and phospholipid secretion was curvilinear. Interestingly, in $(+/-)$ mice a similar curvilinear relation was obtained but at a reduced level. In their mathematical model of biliary lipid secretion, Mazer and Carey (9) described the relation between bile salt and phospholipid secretion by a hyperbolic equation. In this equation, maximal phospholipid output was determined by the maximal rate of synthesis. At the time of their report, there was no reason to invoke the activity of a transporting protein. Our present results, however, strongly suggest that the maximal rate of PC output is not, or at least not exclusively, determined by the maximal synthetic capacity. Although in $(+/+)$ mice the maximal PC output may be partly determined by the maximal synthetic capacity, the strong reduction of PC output by $50 \%$ reduction of mdr 2 Pgp expression in $(+/-)$ mice demonstrates that mdr2 Pgp function is the major regulatory factor in PC secretion. In view of the proposed function of mdr2 Pgp as a PC translocator (see below), it is unlikely that a $50 \%$ reduction of its expression would directly affect the maximal capacity of PC synthesis. This does, however, not exclude that the actual rates of PC synthesis are lower in $(+1$ $-)$ and $(-I-)$ compared to $(+/+)$ mice. That the PC content of the liver is not influenced by the reduced rate of biliary PC output in $(+/-)$ and $(-I-)$ mice (see Table I) suggests that this may be the case; it is possible that the rate of PC secretion determines the rate of synthesis if a feedback mechanism is operative.

Although it may be assumed that the maximal rate of PC secretion is largely determined by the maximal velocity of mdr2 Pgp, the relation between bile salt and phospholipid secretion can probably not be described by a simple hyperbola with $V_{\max }$ of mdr2 Pgp as maximum: in both $(+/+)$ and $(+/-)$ mice, the curve tends to become linear at higher bile salt secretion rates and the slope of this linear part appears similar in both $(+/+)$ and $(+/-)$ mice. As a consequence, the decrease of phospholipid secretion in the $(+/-)$ mice is more pronounced at low rates of bile salt secretion.

To investigate whether the defect in phospholipid secretion in $(-/-)$ mice also pertains at high bile salt flux we infused increasing amounts of taurocholate up to rates that exceeded the transport maximum of these animals. The bile salt transport maxima which were obtained in this way turned out to be different in the three genotypes: a stable maximum output rate of $1,230 \mathrm{nmol} / \mathrm{min}$ per $100 \mathrm{~g}$ was reached in the control mice, while this did not exceed $810 \mathrm{nmol} / \mathrm{min}$ per $100 \mathrm{~g}$ in the heterozygotes and $680 \mathrm{nmol} / \mathrm{min}$ per $100 \mathrm{~g}$ in the homozygotes. In our previous report, we observed an increased bile salt output in $(+I-)$ and $(-I-)$ mice (17). From our present results we can conclude that this increase is caused by an enlarged bile salt pool in these animals $[19.6 \mu \mathrm{mol} / 100 \mathrm{~g}$ in $(-/-)$ vs 12.6 $\mu \mathrm{mol} / 100 \mathrm{~g}$ in $(+/+)$ mice]. This enlargement is most probably due to an increased bile salt synthesis from cholesterol as a consequence of the increased cholesterol content of the liver (Table I). In the experiments of Fig. 3 and Table II, a more reliable estimation of the maximum bile salt transport capacity of the livers of the three mouse genotypes is obtained because bile salts are administered at a continuous high infusion rate. The cause of the decreased maximal bile salt transport capacity of the $(-I-)$ and (to a lesser extent) $(+/-)$ liver is not clear. Indirect evidence has been obtained in the past which indicates that at high bile salt secretion rates vesicular transport of bile salts may contribute to their canalicular secretion (for review see reference 26); colchicine inhibits bile salt secretion at high secretion rates $(27,28)$ and electronmicroscopic studies using antibodies against bile salt have demonstrated an interaction of bile salt with intracellular membranes (29). If PC is supplied via vesicles, the flux of these vesicles will be reduced in $(+1$ $-)$ mice and (almost) absent in ( $/-)$ mice. Thus, if transport of bile salts associated with these vesicles contributes to bile salt secretion, total secretion will be reduced in these animals. However, it is unlikely that such a pathway contributes for as much as $50 \%$ to total bile salt secretion. An additional explanation for the reduced maximal bile salt secretion might be an altered lipid composition of the canalicular plasma membrane in $(-I-)$ and $(+I-)$ mice as compared with $(+I+)$ mice. It is not likely that the reduced bile salt transport is caused by damage to the canalicular membrane; the reduction of transport is already observed at submaximal bile salt transport rates and an intermediate reduction is observed in $(+/-)$ mice which secrete considerable amounts of lipid.

Our results show that under conditions in which endogenous bile salts are secreted in the absence of phospholipid, the disposition of cholesterol into the canaliculus is also severely impaired. Nevertheless, a reduced level of phospholipid secretion is sufficient to reach full cholesterol output, since in the heterozygotes a $50 \%$ reduction in phospholipid secretion had no significant effect on cholesterol output. This suggests that the ratio of phospholipid to cholesterol can vary significantly but that a minimal phospholipid secretion is obligatory for normal cholesterol output. This is in line with the fact that mixed micelles of bile salt and phospholipid have a much higher capacity to take up cholesterol than pure bile salt micelles (30). Alternatively, this observation may support the view that phospholipid and cholesterol are taken from the canalicular membrane as intact units. If this is indeed the case, the changed phospholipid/cholesterol ratio that is observed in bile of the $(+/-)$ mice should also prevail in (the outer leaflet of) the canalicular membrane of these animals.

In accordance with data obtained in other species (31-34), infusion of bile salt into mice at rates equal or above the transport maximum leads to a decline in biliary phospholipid and cholesterol secretion. This was observed both in $(+/+)$ and in $(+/-)$ mice. Surprisingly, in $(-/-)$ mice under conditions of maximal taurocholate infusion cholesterol secretion increased from very low levels to amounts comparable with controls and heterozygotes under the same conditions. The maximal cholesterol output rate in $(-/-)$ mice was $\sim 2.4 \mathrm{nmol} / \mathrm{min}$ per 100 $\mathrm{g}$ and this was $50 \%$ of the maximal output rate in controls and heterozygotes $(5 \mathrm{nmol} / \mathrm{min}$ per $100 \mathrm{~g})$. Under these conditions, phospholipid secretion in the $(-/-)$ mice amounted to 2.2 $\mathrm{nmol} / \mathrm{min}$ per $100 \mathrm{~g}$. Hence, in the $(-/-)$ mice, maximal taurocholate output is able to partially uncouple phospholipid and cholesterol secretion. This could represent the distinction between two types of cholesterol secretion: on the one hand the active, accompanied secretion of cholesterol with phospholipid which represents the major pathway in normal animals and is indirectly dependent on the function of mdr2 Pgp; on the other hand the aspecific extraction of cholesterol and phospholipid 
from the canalicular membrane by bile salt micelles. The question then arises why cholesterol secretion is not observed in the absence of taurocholate infusion. The explanation may be provided by the fact that the endogenous bile salt pool consists of $\sim 30 \%$ cholate and $60 \%$ muricholate. A similar bile salt composition in mice was observed by others (35). After $2 \mathrm{~h}$ of taurocholate infusion, $>95 \%$ of the bile salts consisted of cholate (-conjugates). It has been demonstrated by Montet et al. (36) that $\beta$-muricholate is a very poor solubilizer of cholesterol. In mixtures of $\beta$-muricholate with cholesterol, the bile salt/ cholesterol molar saturation ratio was 1,430 compared with 384 and 24 for ursodeoxycholate and chenodeoxycholate, respectively. In light of these observations, it can be understood that bile containing only cholate-conjugates extracts cholesterol better from the canalicular membrane than a mixture of $\beta$-muricholate and cholate-conjugates.

In the $(-/-)$ mice, a significantly increased bile flow was observed. This phenomenon was especially striking because the glutathione secretion was found to be strongly diminished in these mice (17). Glutathione is thought to drive a substantial fraction of the bile salt-independent bile flow in the rat (37, 38). Our experiments show that the increased flow can be fully attributed to an increase in the bile salt-independent bile flow. One of the possible causes for this phenomenon is the strong ductular proliferation that was observed in $(-1-)$ mice (17). Bile ducts also give rise to water flow (39). In several species including humans, pathological or experimental conditions, which lead to ductular proliferation, give rise to increased bile flow (40-42). However, several other mechanisms are possible as well. The pathology in $(-/-)$ mice could lead to an increased paracellular permeability. Alternatively, a reduction of ductular resorption of biliary solutes could also lead to an increase in bile salt-independent flow. Further experiments are needed to define the exact cause.

What is the mechanism of mdr2 Pgp-mediated PC secretion? As discussed previously (17), the most likely hypothesis is that it translocates PC from the inner to the outer leaflet of the canalicular membrane. Strong support for this model was recently provided by Ruetz and Gros (43), who expressed mdr2 Pgp in secretory vesicles of a yeast sec mutant and demonstrated ATP-dependent translocation of a fluorescent PC analogue between the leaflets of the membrane. Primary active PC translocation can lead to phospholipid imbalance between the two leaflets of the membrane leading to increased lateral pressure in the outer leaflet. As a consequence, instable structures may be induced which give rise to vesiculation of $\mathrm{PC}$ from the outer leaflet. Luminal bile salts may act to facilitate this process by inserting into the outer leaflet. The fatty acid composition of $\mathrm{PC}$ in bile differs from that in the canalicular membrane ( $\mathrm{C}_{16: 0} \mathrm{C}_{18: 2}$ and $\mathrm{C}_{16: 0} \mathrm{C}_{18: 1}$ vs $\mathrm{C}_{18: 0} \mathrm{C}_{20: 4}$, respectively) (6). To explain this specific composition it has to be assumed in this model that vesiculation occurs from microdomains in the outer leaflet that are rich in these PC species. Such microdomains may be created by the translocating action of Pgp but how they are maintained is not clear. It has been demonstrated that the apical domain of other epithelial cell types contains a high amount of glycosphingolipids which have a strong tendency to cluster by hydrogen bonding $(44,45)$. If this is also the case for the canalicular membrane of hepatocytes, this may provide a mechanism for the repulsion of PC into microdomains.

Assuming that the protein indeed acts as a flippase, its role in PC secretion will depend strongly on the mechanism of intracellular PC transport. Two mechanisms have been proposed.
Firstly, the abundant cytosolic PC transfer protein (15) may take up PC from the endoplasmic reticulum (ER) and donate it to the inner leaflet of the canalicular membrane. In a preliminary report, Cohen et al. (16) have shown that such transfer can be mimicked with a mixture of ER- and canalicular-like membranes, albeit that in this experimental system the canalicularlike acceptor membranes were essentially free of PC. They also showed that bile salts promote this process. The important consequence of such a mechanism is that PC is exclusively donated to the inner leaflet. In this mechanism the role of mdr2 Pgp as a flippase is straightforward; the protein flips PC to the outer leaflet where it is either taken up directly in bile salt micelles or vesiculates under the influence of bile salts.

Secondly, insertion of PC into the canalicular membrane may occur via PC-rich vesicles that are derived from the ER. In the past, several groups have provided indirect evidence for this mechanism by showing that lipid secretion can be inhibited by colchicine (and vinblastine) $(26-28,46)$. Since these compounds inhibit microtubular function, it was suggested that vesicular transport must be involved in the lipid secretion process. These putative PC-rich vesicles are derived from the ER where $\mathrm{PC}$ is synthesized. Since a PC-specific flippase in this organelle ensures the symmetric distribution of PC (47), fusion of these vesicles with the canalicular membrane inserts $P C$ in both leaflets of the bilayer. It is difficult to reconcile this mechanism of PC transport with the almost complete abrogation of PC secretion in the $(-l-)$ animal. Clearly, additional studies are required to answer the intriguing questions generated in the present study.

\section{Acknowledgments}

We thank Professor Piet Borst for critical and inspiring discussions; Professor Don Ostrow for critically reviewing the manuscript; and Alie Nijenhuis for skillful GC-MS determination of bile salt species.

This study was supported in part by KWF grants NKI 88-6 and NKI 92-41 to Professor P. Borst.

\section{References}

1. Coleman, R., S. Iqbal, P. P. Godfrey, and D. Billington. 1979. Membranes and bile formation. Composition of several mammalian biles and their membrane damaging properties. Biochem. J. 178:201-208.

2. Velardi, A., A. K. Groen, R. P. J. Oude Elferink, R. v. d. Meer, G. Palasciano, and G. N. J. Tytgat. 1991. Cell type dependent effect of phospholipid and cholesterol on bile salt cytotoxicity. Gastroenterology. 101:457-464.

3. Sagawa, H., S. Tazuma, and G. Kajiyama. 1993. Protection against hydrophobic bile salt induced cell membrane damage by liposomes and hydrophilic bile salts. Am. J. Physiol. 264:G835-G839.

4. Coleman, R. 1987. Biochemistry of bile secretion. Biochem. J. 244:249 261.

5. Marzolo, M. P., A. Rigotti, and F. Nervi. 1990. Secretion of biliary lipids from the hepatocyte. Hepatology. 12:134S-142S.

6. Coleman, R., and K. Rahman. 1992. Lipid flow in bile formation. Biochim. Biophys. Acta. 1125:113-133.

7. Swell, L., C. C. Bell, and C. Entenman. 1968. Bile acids and lipid metabolism. III. Influence of bile acids on phospholipids in liver and bile of the isolated perfused dog liver. Biochim. Biophys. Acta. 164:278-284.

8. Wheeler, H. O., and K. K. King. 1972. Biliary excretion of lecithin and cholesterol in the dog. J. Clin. Invest. 51:1337-1350.

9. Mazer, N. A., and M. C. Carey. 1984. Mathematical model of biliary lipid secretion: a quantitative analysis of physiological and biochemical data from man and other species. J. Lipid Res. 25:932-953.

10. Coleman, R., K. Rahman, K. Kan, and R. A. Parslow. 1989. Retrograde intrabiliary injection of amphipatic materials causes phospholipid secretion into bile. Biochem. J. 258:17-22.

11. Lowe, P. J., S. G. Barnwell, and R. Coleman. 1984. Rapid kinetic analysis of the bile salt-dependent secretion of phospholipid, cholesterol and a plasma membrane enzyme into bile. Biochem. J. 222:631-637. 
12. Balint, J. A., D. A. Beeler, E. C. Kyriakides, and D. H. Treble 1971. The effect of bile salts upon lecithin synthesis. J. Lab. Clin. Med. 77:122-133.

13. Sakisaka, S., O. C. Ng, and J. L. Boyer. 1988. Tubulovesicular transcytotic pathway in isolated rat hepatocyte couplets in culture. Effect of colchicine and taurocholate. Gastroenterology. 95:793-804

14. Hayakaka, T., S. Sakisaka, P. J. Meier, and J. L. Boyer. 1990. Taurocholate stimulates transcytotic vesicular pathways labeled by horseradish peroxidase in the isolated perfused rat liver. Gastroenterology. 99:216-228.

15. Wirtz, K. W. A. 1991. Phospholipid transfer proteins. Annu. Rev. Biochem. 60:73-99.

16. Cohen, D. E., M. R. Leonard, and M. C. Carey. 1992. Submicellar bile salt concentrations stimulate biliary phosphatidylcholine (PC) transfer from mode endoplasmic reticulum to canalicular membranes via hepatic PC-transfer protein. Hepatology. 16:90a. (Abstr.)

17. Smit, J. J. M., A. H. Schinkel, R. P. J. Oude Elferink, A. K. Groen, E. Wagenaar, L. van Deemter, C. A. A. M. Mol, R. Ottenhoff, N. M. T. van de Lugt, M. A. van Roon, et al. 1993. Homozygous disruption of the murine $m d r 2$ P-glycoprotein gene leads to a complete absence of phospholipid from bile and to liver disease. Cell. $75: 451-462$.

18. Gottesman, M. M., and I. Pastan. 1993. Biochemistry of multidrug resistance mediated by the multidrug transporter. Annu. Rev. Biochem. 62:385-427.

19. Buschman, E., R. J. Arceci, J. M. Croop, M. Che, I. M. Arias, D. E Housman, and P. Gros. 1992. $m d r 2$ encodes P-glycoprotein expressed in the bile canalicular membrane as determined by isoform-specific antibodies. J. Biol. Chem. 267:18093-18099.

20. Higgins, C. F., and M. M. Gottesman. 1992. Is the multidrug transporter a flippase? Trends Biochem. Sci. 17:18-21.

21. Homolya, L., Z. Hollo, U. A. Germann, I. Pastan, M. M. Gottesman, and B. Sarkadi. 1993. Fluorescent cellular indicators are extruded by the multidrug resistance protein. J. Biol. Chem. 268:21493-21496.

22. Gurantz, D., M. F. Laker, and A. F. Hofmann. 1981. Enzymatic measurement of choline containing phospholipids in bile. J. Lipid Res. 22:373-376.

23. Allain, C. C., L. S. Poon, C. S. G. Chan, W. Richmond, and P. C. Fu. 1974. Enzymatic determination of total serum cholesterol. Clin. Chem. 20:470475.

24. Turley, S. D., and J. M. Dietschy. 1978. Reevaluation of the 3-hydroxysteroid dehydrogenase assay for total bile acids in bile. J. Lipid Res. 19:945-955.

25. Parmentier, G. G., G. A. Janssen, E. A. Eggermon, and H. J. Eyssen. 1979. $C_{27}$ bile acids in infants with coprostanic acidemia and occurrence of a $3 \alpha, 7 \alpha, 12 \alpha$-trihydroxy-5 $\beta-\mathrm{C}_{29}$ dicarboxylic bile acid as a major component in their serum. Eur. J. Biochem. 102:173-183.

26. Crawford, J. M., and J. L. Gollan. 1991. Transcellular transport of organic anions in hepatocytes: still a long way to go. Hepatology. 14:192-197.

27. Barnwell, S. G., P. J. Lowe, and R. Coleman. 1984. The effects of colchicine on secretion into bile of bile salts, phospholipids, cholesterol and plasma membrane enzymes: bile salts are secreted unaccompanied by phospholipids and cholesterol. Biochem. J. 220:723-731.

28. Crawford, J. M., C. A. Berken, and J. L. Gollan. 1988. Role of the hepatocyte microtubular system in the excretion of bile salts and biliary lipid: implications for intracellular vesicular transport. J. Lipid Res. 29:144-156.

29. Lamri, Y., A. Roda, M. Dumont, G. Feldmann, and S. Erlinger. 1988
Immunoperoxidase localization of bile salts in rat liver cells. Evidence for a role of the Golgi apparatus in bile salt transport. J. Clin. Invest. 82:1173-1182.

30. Carey, M. C., and D. M. Small. 1978. The physical chemistry of cholestero solubility in bile. Relationship to gallstone formation and dissolution in man. $J$. Clin. Invest. 61:998-1026.

31. Hardison, W. G. M., D. E. Hatoff, K. Miyai, and R. G. Weiner. 1981 Nature of bile acid maximum secretory rate in the rat. Am. J. Physiol. 241:G337G343.

32. Barnwell, S. G., B. Tuchweber, and I. M. Yousef. 1987. Biliary lipid ecretion in the rat during infusion of increasing doses of unconjugated bile acids. Biochim. Biophys. Acta. 922:221-233.

33. Yousef, I. M., S. Barnwell, F. Gratton, B. Tuchweber, A. M. Weber, and C. C. Roy. 1987. Liver cell membrane solubilization may control maximum secretory rate of cholic acid in the rat. Am. J. Physiol. 252:G84-G91.

34. Yousef, I. M., D. Mignault, and B. Tuchweber. 1992. Effect of complete sulfation of bile acids on bile formation: role of conjugation and number of sulfate groups. Hepatology. 15:438-445.

35. Uchida, K., T. Akiyoshi, H. Igimi, H. Takase, Y. Nomura, and S. Ishihara. 1991. Differential effects of ursodeoxycholic acid and ursocholic acid on the formation of biliary cholesterol crystals in mice. Lipids. 26:526-530.

36. Montet, J.-C., M. Parquet, E. Sacquet, A.-M. Montet, R. Infante, and J. Amic. 1987. $\beta$-muricholic acid; potentiometric and cholesterol-dissolving properties. Biochim. Biophys. Acta. 918:1-10.

37. Ballatori, N., and A. T. Truong. 1989. Relation between biliary glutathione excretion and bile acid dependent bile flow. Am. J. Physiol. 256:G22-G30.

38. Ballatori, N., and A. T. Truong. 1992. Glutathione as a primary osmotic driving force in hepatic bile formation. Am. J. Physiol. 263:G617-G624.

39. Erlinger, S. 1987. Physiology of bile secretion and enterohepatic circulation. In Physiology of the Gastrointestinal Tract. L. R. Johnson, editor. Raven Press, New York. 1557-1580.

40. Bode, C., O. Zelder, H. Goebell, and H. O. Neuberger. 1972. Choleresis induced by secretin: distinctly increased response in cirrhotics. Scand. J. Gastroenterol. 7:697-699.

41. Turnberg, L. A., E. A. Jones, and S. Sherlock. 1968. Biliary secretion in a patient with cystic duct dilatation of the intrahepatic biliary tree. Gastroenterology. $54: 1155-1161$

42. Alpini, G., R. Lenzi, L. Sarkozi, and N. Tavoloni. 1988. Biliary physiology in rats with bile ductular hyperplasia. Evidence for a secretory function of proliferated bile ductules. J. Clin. Invest. 81:569-578.

43. Ruetz, S., and P. Gros. 1994. Phosphatidylcholine translocase: a physiological role for the $m d r 2$ gene. Cell. 77:1071-1082.

44. Simons, K., and G. van Meer. 1988. Lipid sorting in epithelial cells. Biochemistry. 27:6197-6202.

45. Thompson, T. E., and T. W. Tillack. 1985. Organization of glycosphingolipids in bilayers and plasma membranes of mammalian cells. Annu. Rev. Biophys. Bioeng. 14:361-386.

46. Gregory, D. H., Z. R. Vlahcevic, M. F. Prugh, and L. Swell. 1978. Mechanism of secretion of biliary lipids: role of a microtubular system in hepatocellular transport of biliary lipids in the rat. Gastroenterology. 74:93-100.

47. Bishop, W. R., and R. M. Bell. 1985. Assembly of the endoplasmic reticulum phospholipid bilayer: the phosphatidylcholine transporter. Cell. 42:5160 